\title{
Terapia Ocupacional no campo social no Brasil e na América Latina: panorama, tensóes e reflexóes a partir de práticas profissionais ${ }^{1}$
}

\author{
Roseli Esquerdo Lopes ${ }^{\mathrm{a}}$, Patrícia Leme de Oliveira Borba ${ }^{\mathrm{b}}$, \\ Carla Regina Silva ${ }^{c}$, Ana Paula Serrata Malfitano ${ }^{d}$
}

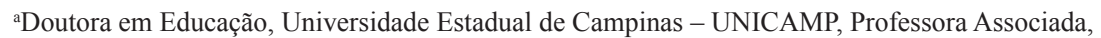 \\ Departamento de Terapia Ocupacional e dos Programas de Pós-Graduação em Educação e em Terapia \\ Ocupacional, Universidade Federal de São Carlos - UFSCar, São Carlos, SP, Brasil \\ bDoutoranda e Mestre em Educação, Universidade Federal de São Carlos - UFSCar, \\ Professora Assistente, Departamento de Saúde, Educação e Sociedade, \\ Universidade Federal de São Paulo - UNIFESP, Santos, SP, Brasil

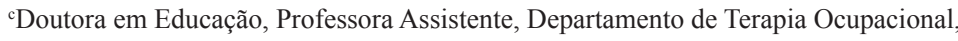 \\ Universidade Federal de São Carlos - UFSCar, São Carlos, SP, Brasil \\ dDoutora em Saúde Pública, Universidade de São Paulo - USP, Professora Adjunta, \\ Programa de Pós-Graduação em Terapia Ocupacional, Departamento de Terapia Ocupacional, \\ Universidade Federal de São Carlos - UFSCar, São Carlos, SP, Brasil
}

\begin{abstract}
Resumo: O campo social vem se configurando como um espaço crescente de intervenções, formação e pesquisa na área de terapia ocupacional. Assim, com o intuito de se conhecer a divulgação de produções nesse âmbito, foram analisados os trabalhos submetidos ao Eixo "Práticas em Terapia Ocupacional" e aprovados para apresentação no XII Congresso Brasileiro de Terapia Ocupacional e IX Congresso Latino-americano de Terapia Ocupacional, realizados em 2011. Do total de trabalhos aprovados (607), a partir da leitura de todos os resumos, buscaram-se aqueles que explicitamente se colocavam no campo social. Foram selecionados 44 trabalhos e classificados de acordo com a região geográfica de origem, a vinculação com Instituições de Ensino Superior, assim como com a população-alvo das ações. Os resultados demonstram que a infância, adolescência e a juventude são públicos prioritários nas intervenções nesse campo. A assistência social é o setor com maior agrupamento de trabalhos, com destaque para aqueles que demonstram articulações intersetoriais. Sobre as principais temáticas da intervenção terapêutica-ocupacional foi possível correlacioná-las a: equipamento ou política específica; grupo populacional; estratégias utilizadas; relatos apresentados; e, ainda, a propostas de formação profissional na área. Verifica-se a necessidade de divulgação acerca dos trabalhos no campo social, sua ampliação quantitativa e qualitativa e de integração entre eles, incluindo um maior debate no interior da profissão. Aponta-se o caminho do aprimoramento das referências teóricas e metodológicas envolvidas para que a categoria profissional possa se fortalecer e, de fato, responder às inúmeras demandas sociais apresentadas a diversas categorias profissionais, entre elas, a terapia ocupacional.
\end{abstract}

Palavras-chave: Terapia Ocupacional/Tendências, Terapia Ocupacional, Condições Sociais, Publicações de Divulgação Cientifica.

Autor para correspondência: Roseli Esquerdo Lopes, Laboratório METUIA, Departamento de Terapia Ocupacional, Universidade Federal de São Carlos - UFSCar, Rod. Washington Luís, Km 235, CEP 13565-905, São Carlos, SP, Brasil, e-mail: relopes@ufscar.br 


\title{
The social field of Occupational Therapy in Brazil and Latin America: overview, tensions and reflections from professional practices
}

\begin{abstract}
The social field has emerged as a growing space for assistance, formation and research in the occupational therapy area. Thus, in order to know the disclosure of productions in this context, the papers submitted to the Axis "Practices in Occupational Therapy" and approved for presentation at the XII Brazilian Congress of Occupational Therapy and IX Latin American Congress of Occupational Therapy, held in 2011, were analyzed. From the total amount of approved papers (607), through the reading of all the abstracts, those that were explicitly placed in the social field were searched for selection. Forty-four studies were selected and sorted according to their geographical origin, their linking to the universities and the target population of their actions. The results showed that child, adolescent and young populations are the priority public of the interventions in this field. Social assistance is the sector with the largest grouping of studies, especially those that show intersectoral articulations. On the main themes of occupational therapy, assistance was correlated with the following: institution or specific policy; population group; strategies used; reports submitted; and proposals for the professional training area. It was possible to notice the necessity to disseminate information about the studies in the social field, the need of quantitative and qualitative increase of the studies as well as their integration, including more intense debate within the profession. This research points the way to the improvement of theoretical references and methodological approaches for the professional category, so that it can actually be consolidated, responding to the numerous social demands presented to several professional categories, including occupational therapy.
\end{abstract}

Keywords: Occupational Therapy/Trends, Occupational Therapy, Social Conditions, Disclosure of Scientific Publications.

\section{Introdução}

Nos últimos quatorze anos, o METUIA ${ }^{2}$ tem investido na realização de projetos e programas de ensino, pesquisa e extensão universitária na direçáo de construir um arcabouço teórico e prático que contribua com a discussão acerca das intervençôes e da produçáo de conhecimento sobre o campo social na terapia ocupacional, alinhados a referenciais teóricos e metodológicos da Terapia Ocupacional Social (BARROS; GHIRARDI; LOPES; 1999, 2002; BARROS; LOPES; GALHEIGO; 2007b).

No bojo das atividades realizadas durante o XII Congresso Brasileiro de Terapia Ocupacional (CBTO) e IX Congresso Latino-americano de Terapia Ocupacional (CLATO), que ocorreram na cidade de São Paulo, em outubro de 2011, organizado pela Associaçáo dos Terapeutas Ocupacionais do Estado de São Paulo (ATOESP), com o apoio da Associação Brasileira de Terapia Ocupacional (ABRATO) e da Confederação Latino-americana de Terapia Ocupacional (CLATO), evento de maior relevância para a área, no contexto da América Latina, propusemos o II Simpósio Internacional de Terapia Ocupacional Social (SITOS) ${ }^{3}$. Seu intuito foi o de promover espaços para o debate científico, de âmbito nacional e internacional, visando ao aprofundamento de questôes relativas às práticas profissionais, à definição dos temas relevantes para a pesquisa e para o ensino na área e ao estabelecimento de estratégias para o acompanhamento e monitoramento da atuação da terapia ocupacional nos serviços e projetos socioculturais, socioassistenciais e educacionais.

Uma das estratégias da organização foi reservar um espaço na programaçáo, denominado "Conhecendo Experiências em Terapia Ocupacional Social”, no qual, a partir da organizaçáo visual, espacial e de conteúdos dos trabalhos encaminhados e aprovados pela Comissão Científica do XII CBTO e IX CLATO, no Eixo das "Práticas de Terapia Ocupacional" apresentasse um retrato de propostas no campo da terapia ocupacional social e, analisando-se os seus conteúdos, fosse feita uma síntese e o debate dos principais caminhos que vêm sendo tomados pela terapia ocupacional social'5.

Assim, tendo-se em mãos os 607 resumos aprovados para apresentação e disponibilizados pela Comissão Organizadora do evento geral, foram selecionados 44 trabalhos da área social (CONGRESSO..., 2011), os quais foram analisados por nós e compuseram os dados sobre os quais discorremos adiante. Tal número, 44 (7,25\% do total), revela uma tendência de aumento no montante de trabalhos da área em eventos da terapia ocupacional. 
Reis, Barros e Uchidomari (2010) discutem os trabalhos da área social apresentados nos Congressos Brasileiros de Terapia Ocupacional de 1997 a 2007, demonstrando que: em 1997, apenas um trabalho, dos 32 apresentados, referia-se à área social (3,12\%); em 1999, se obtiveram 13 trabalhos do cômputo de 260 (5\%); em 2001, contaram-se 23 de um total de 421 (5,46\%); em 2003, foram 14 em 247 (5,67\%); em 2005, totalizaram-se 21 entre os 439 aprovados (4,78\%); e, em 2007, ano da realização do I Simpósio Internacional de Terapia Ocupacional Social, foram apresentados 33 trabalhos da área, entre os 472 (7\%) do total da programação (REIS; BARROS; UCHIDOMARI; 2010). É importante que se considere nessa série que na sua edição de 2011 o Congresso Brasileiro ocorreu junto com o Congresso Latino-americano de Terapia Ocupacional, o que, com relação aos eventos considerados, ocorreu igualmente, apenas, em 2003.

Ao relatarmos as informaçóes presentes nos trabalhos selecionados, propomos uma visáo panorâmica sobre a terapia ocupacional no campo social, sem a pretensão de abarcarmos todas as discussóes desse campo profissional, como também das múltiplas práticas em desenvolvimento na área. Trata-se de um "sobrevoo" sem a intenção de classificação, categorização ou valoração - positiva ou negativa - acerca da qualidade das referências conceituais refletidas na prática profissional de colegas, descrita e sintetizada nas restritas linhas de um resumo científico. Explicitamos os limites da proposta realizada, juntamente com a manifestação de um profundo respeito a todos os profissionais que empreendem - coletiva ou individualmente - seus voos e pousos diários nessa área. Contudo, o esforço de conhecermos e divulgarmos as práticas em destaque, veiculadas em eventos da área, é de grande relevância para que possamos apreender, mesmo que inicialmente, o "estado da arte" das açóes em terapia ocupacional desenvolvidas no campo social.

Dados os enormes desafios sociais que as sociedades têm enfrentado, em especial a latino-americana, com relação aos quais é indispensável um olhar sobre sua construção histórica e sobre as inúmeras demandas macro e micro sociais decorrentes, evidencia-se a necessidade de uma série de açóes e de respostas, a respeito das quais as categorias profissionais devem estar preparadas e comprometidas de forma técnica, política e ética. Nesse sentido, a terapia ocupacional assume também sua responsabilidade na construção de um instrumental teórico-prático para promover melhores intervençóes e análises sociais. Entretanto, nossa trajetória predominante no campo da saúde, bem como a história em torno de práticas assistencialistas, requer uma ponderação crítica em torno das intervençôes que vêm sendo efetuadas, das formas empreendidas; dito de outro modo, é necessário que se reconheçam e se discutam as técnicas criadas/reproduzidas para respaldar as açóes.

Com o que aqui trazemos, esperamos contribuir com o debate, na direção de criar subsídios analíticos para que nossas açóes profissionais possam ser traduzidas pela competência técnica adquirida pela prática cotidiana reflexiva (FREIRE, 1978), juntamente com a sua divulgaçáo, em fóruns da terapia ocupacional e de outras áreas com as quais fazemos interface.

\section{0 processo de seleção e análise dos trabalhos}

Nossa preocupação com a realização do II Simpósio Internacional de Terapia Ocupacional Social (SITOS) era fomentar espaços para o debate e para a troca entre os terapeutas ocupacionais, fossem profissionais e/ou pesquisadores. Indagaçóes em torno do posicionamento profissional no campo social, os referenciais utilizados, os recursos aplicados, os lugares de ação, as reflexóes advindas e a fundamentação que alicerça as práticas eram pontos motivadores para a composiçáo do evento.

Para levarmos esse ideário a algo concreto, compartilhado e que possibilitasse uma valorização dos autores dos trabalhos, inicialmente propusemos à Comissão Organizadora do XII CBTO e IX CLATO que, no ato da inscrição, a pessoa que submetesse um trabalho ao Eixo "Práticas em Terapia Ocupacional" indicasse a área pretendida, dentre elas, a área social, com o intuito de que náo ficasse sobre nosso crivo o processo de seleção, mas sim a critério dos próprios autores, incluindo a escolha para participação ou não no II SITOS, dado que muitas atividades ocorreriam simultaneamente. No entanto, a referida Comissão avaliou que essa proposta geraria custos adicionais, uma vez que o sistema de inscrição e submissão de trabalhos estava já finalizado pela empresa contratada, inviabilizando nossa proposta inicial.

Uma iniciativa dos organizadores do evento geral foi o envio de uma mensagem eletrônica a todos os autores de trabalhos aprovados no evento com a solicitação de que classificassem a área de seus trabalhos de acordo com as áreas de "especialidades" definidas pelo Conselho Federal de Fisioterapia e Terapia Ocupacional, para o terapeuta ocupacional, a saber: Saúde Mental, Saúde Funcional, 
Saúde Coletiva, Saúde da Família, Contextos Sociais, Contextos Hospitalares e Acupuntura (CONSELHO..., 2009). Contudo, essa classificação não é consensual na categoria, envolvendo recentes debates e polêmicas em torno das "especialidades" em terapia ocupacional. Assim, poucas pessoas responderam a tal solicitação.

Sem a possibilidade de definição pelo próprio autor, nossa opção foi realizar uma seleção após a aprovação dos trabalhos submetidos àquele eixo do XII CBTO e IX CLATO, na medida em que se propunha agregar as questôes em torno das práticas terapêutico-ocupacionais, incluindo aquelas da área social, a fim de delinearmos um quadro inicial.

A metodologia utilizada adotou como primeiro critério a exclusão de todos os trabalhos (resumos ou trabalhos completos) cujas palavras do título já indicassem práticas em outras áreas de atuação da terapia ocupacional, tais como reabilitação/disfunção física ou saúde mental, assim como a existência de termos técnicos, nomes de doenças, síndromes ou terminologias de sintomas, agravos e sequelas, que não se aplicariam aos conteúdos da área social.

Optamos por uma classificação que respeitou uma diretriz inclusiva de temáticas para que, no momento seguinte, pudéssemos nos dedicar à leitura cuidadosa de todos os resumos. Privilegiamos a escolha dos trabalhos a partir de temáticas com relação as quais o campo social brasileiro tem se dedicado nos últimos 30 anos; guiando-nos, sobretudo, pela proposta de incorporar trabalhos que voltassem suas práticas para públicos fora do eixo estruturador do binômio saúde/doença ou de seus agravos e que se debruçassem sobre estudos e/ou práticas relacionadas a políticas, instituiçôes e a serviços ligados aos setores da educaçáo, assistência social e cultura.

Como colocado anteriormente, essa análise resultou na seleção de 44 trabalhos considerados pertinentes ao campo social, ou seja, 7,25\% dentre todos aqueles inscritos e aprovados no eixo "Práticas em Terapia Ocupacional” do evento (607).

Com o intuito de traçar novas estratégias de agremiação das pessoas, trabalhamos junto à Comissão Organizadora para que esses trabalhos tivessem sua apresentaçáo concentrada no dia do Simpósio, o que foi viabilizado no fechamento da programação completa dos eventos. Além disso, elaboramos e solicitamos o encaminhamento de uma carta, o que foi feito, a cada um dos autores que teve seu trabalho classificado no campo social, convidando-os à participação no II SITOS.

\section{Resultados}

No interior dos 44 trabalhos selecionados, buscamos sua origem geográfica (Figura 1), traçando uma comparação entre o total de trabalhos do eixo "Práticas em Terapia Ocupacional" e aqueles do campo social.

Observamos haver uma aproximação no cenário brasileiro entre os percentuais gerais e aqueles da área estudada. Há um acréscimo percentual referente aos trabalhos na área social apresentados pela Argentina e pelo Chile e, no caso da Colômbia, o único trabalho aprovado referia-se ao campo social.

Enfocando especificamente o cenário brasileiro, do total de trabalhos apresentados (576), temos a distribuiçáo por região administrativa conforme apresentado na Figura 2.

Analisando o total de trabalhos, constata-se uma alta concentração na região Sudeste, com 343 trabalhos (60\%), destacando-se o Estado de São Paulo, com 253 trabalhos (42\%). Na sequência, temos a regiáo Nordeste contando com 103 (18\%), a Norte com $62(10,8 \%)$, a Sul com $47(8,2 \%)$ e a regiāo Centro-Oeste com 18 (3\%).

Tal concentraçáo pode ser explicada por um conjunto de fatores associados à terapia ocupacional. Segundo informaçóes disponíveis no sítio eletrônico do Conselho Federal de Fisioterapia e Terapia Ocupacional (2012) há, no Brasil, 13.536 profissionais registrados. Desses, 4.382 são cadastrados no Estado de São Paulo, por meio do Conselho Regional de Fisioterapia e Terapia Ocupacional da Terceira Regiáo (2012), cuja jurisdição corresponde exclusivamente ao Estado de Sáo Paulo. Portanto, cerca de 33\% dos profissionais brasileiros são de São Paulo. Além desse fator, esse Estado concentra importantes universidades públicas, que têm atuaçáo destacada na produção de conhecimento no Brasil em geral e na terapia ocupacional em particular, e que articulam a divulgação de seus produtos em fóruns acadêmicos e profissionais. Por fim, é preciso registrar que o presente evento ocorreu na cidade de São Paulo, facilitando a participação de terapeutas ocupacionais residentes e atuantes nesse Estado.

Comparando os dados nacionais com aqueles relacionados ao campo social, observa-se uma distribuição equânime entre os trabalhos, ou seja, os estados com maior produção são também aqueles que apresentaram mais trabalhos relacionados ao campo social. Destaca-se, uma vez mais, a grande proporção de trabalhos advindos do Estado de São Paulo. Esse fato tem sido recorrente nos Congressos Brasileiros da área. Segundo Reis, Barros e Uchidomari (2010), 


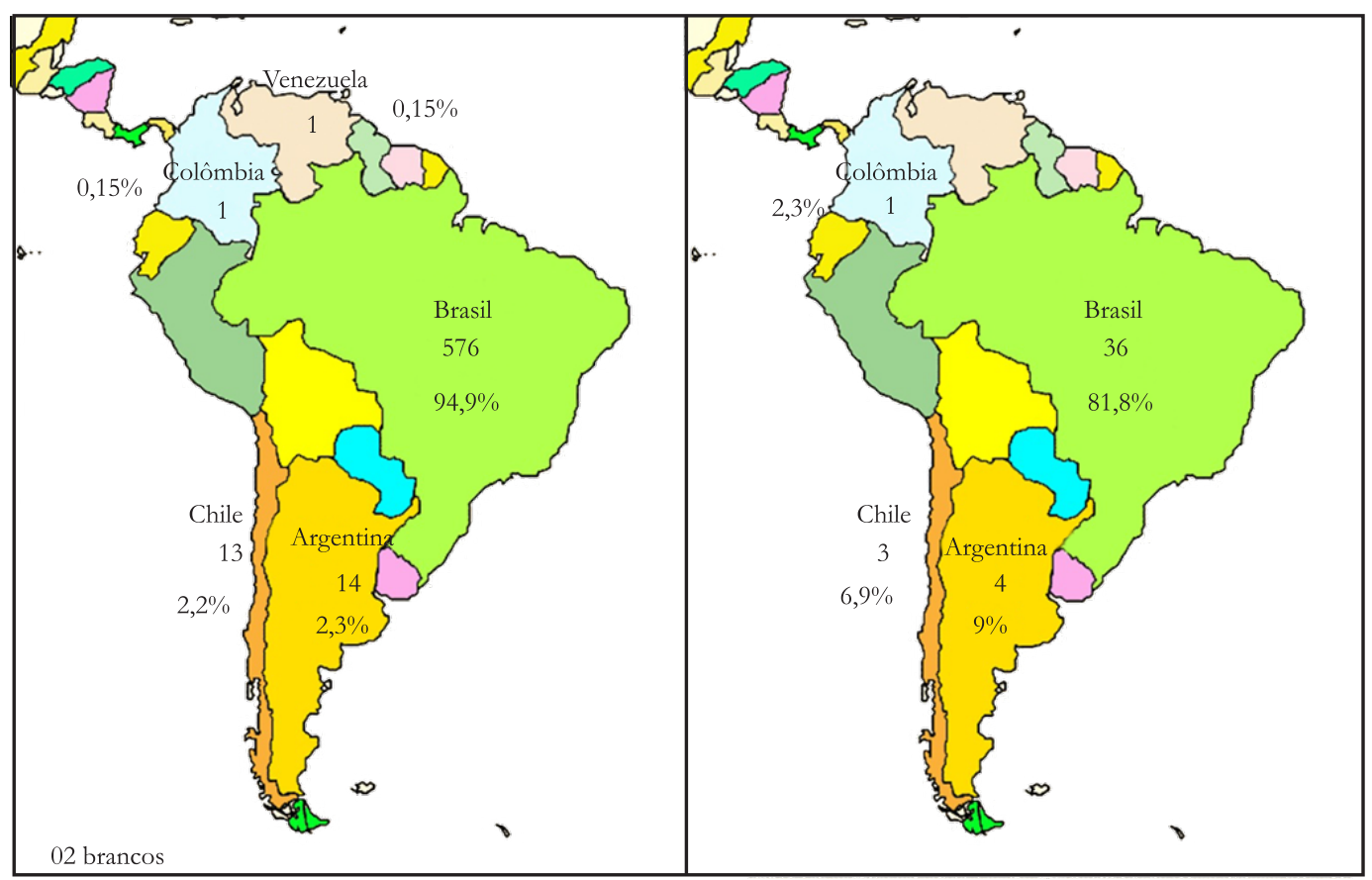

Figura 1. Representação por países da América Latina dos trabalhos aprovados no Eixo "Práticas em Terapia Ocupacional” e daqueles referentes ao campo social no XII CBTO e IX CLATO.
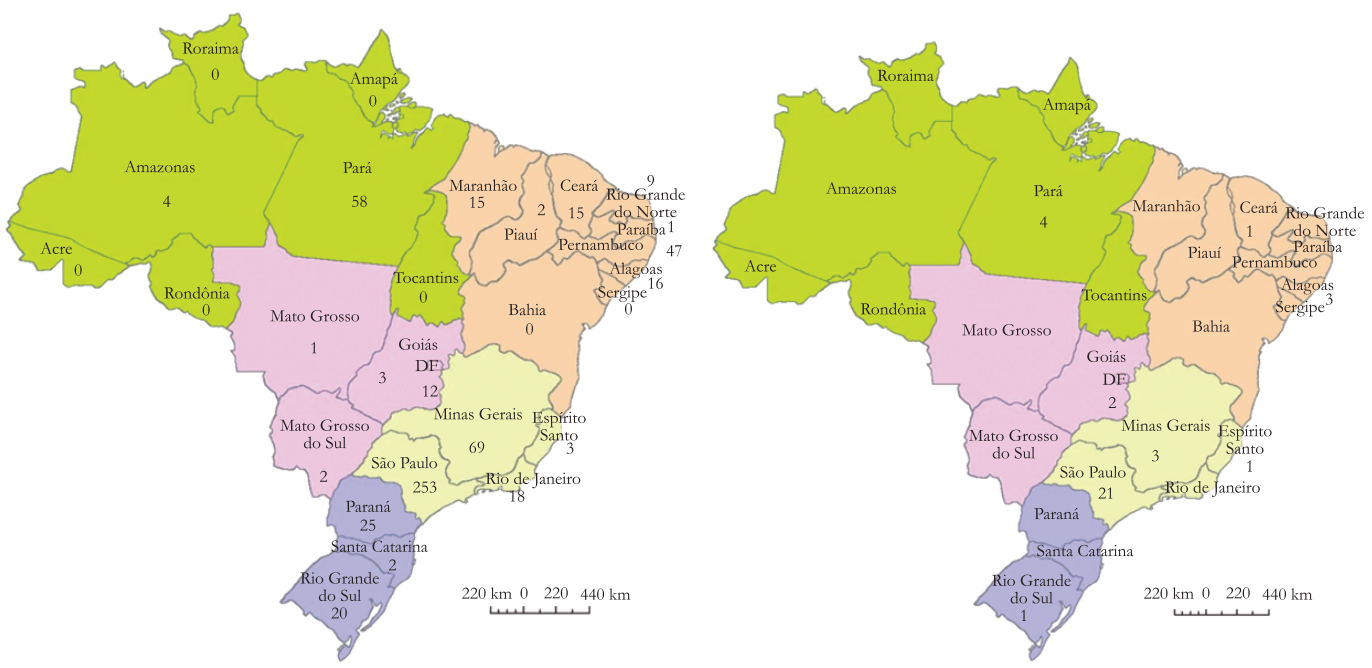

Figura 2. Representação por estados brasileiros dos trabalhos aprovados no eixo "Práticas em Terapia Ocupacional” e daqueles referentes ao campo social no XII CBTO e IX CLATO.

entre 1997 e 2007, 84\% dos trabalhos apresentados eram provenientes de autores de São Paulo. $\mathrm{Na}$ edição de 2011, dos 36 trabalhos brasileiros, 21 eram paulistas (58\%).

Outra questão que logo se evidenciou na análise dos resumos se referia à alta vinculação dos trabalhos com o desenvolvimento de projetos em Instituições de Ensino Superior (IES), na condição de pesquisa e/ou de práticas extensionistas; igualmente relacionada à ação no Ensino Superior, foi a presença de relatos sobre a formação de terapeutas ocupacionais para o campo social, no interior dos cursos de graduação. Assim, consideramos importante levantar esse dado e realizar a comparação com relação a todos os trabalhos do Eixo "Práticas de Terapia Ocupacional", buscando compreender se a inserção não majoritária 
da área exigiria mais das universidades em termos de práticas inovadoras, que pudessem a posteriori criar inserção da categoria profissional, ou se essa era uma realidade para todas as áreas.

Ainda que os eventos científicos sejam realizados também para integrar o universo prático profissional e o acadêmico, assistimos a uma forte atuação das IES nesses espaços, afinal uma de suas tarefas é a divulgação do conhecimento; dessa forma, como se pode observar na Figura 3, se sobressaem de modo importante os percentuais de trabalhos vinculados às Instituiçôes de Ensino Superior. Podemos ventilar a hipótese de que os trabalhos relacionados à terapia ocupacional no campo social estavam mais vinculados às universidades por sua natureza no que tange à demonstração e inovação teórica e prática, bem como por lidar igualmente com problemáticas/ áreas menos relacionadas aos interesses do mercado. Porém, a diferença é pequena quando comparada ao total de trabalhos, trazendo o questionamento acerca do público que está sendo atingido pelos eventos da área e sobre a possibilidade de existência de práticas desconhecidas, realizadas nos contextos concretos de atuação profissional. Nessa perspectiva, nos perguntamos qual a implicação de tal questáo para uma análise contemporânea do campo de atuação profissional. Certamente, não é possível realizar generalizaçôes que falem em nome de uma totalidade da área de terapia ocupacional.

Outra correlação possível diz respeito ao número de autores envolvidos nos trabalhos apresentados. Percebemos que $86 \%$ dos trabalhos possuíam dois ou mais autores ${ }^{6}$ e apenas seis trabalhos (14\%) possuíam um único autor. Esse dado nos revela a alta concentração de coautorias, demonstrando o desenvolvimento de trabalhos coletivos na área. Se somarmos todos os autores, sem a distinção entre aqueles que se repetem, temos 151 autores.

A terceira fase dos procedimentos correspondeu à análise de todos os resumos acerca da compreensão metodológica e prática propostas. Como resultado, obtivemos a categorização de três principais elementos: Público Atendido (Figura 4), respeitando-se os termos utilizados pelos autores; Setor de Vinculação; e Temática.

A predominância de intervençóes desenvolvidas com o público infantil por terapeutas ocupacionais
Trabalhos do eixo "Prática em Terapia Ocupacional"

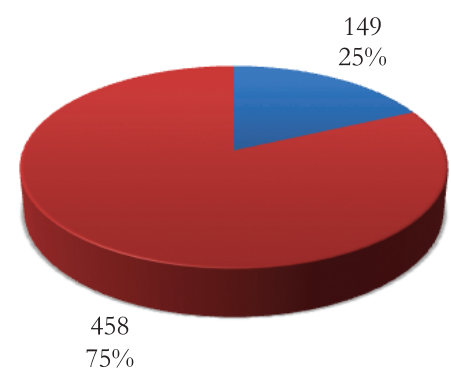

Trabalhos do campo social

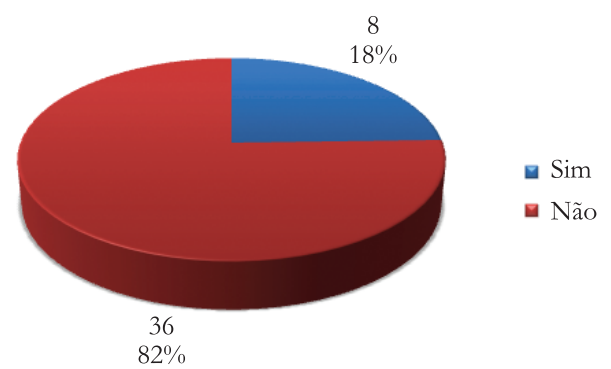

Figura 3. Vinculação dos trabalhos com instituições de ensino superior.

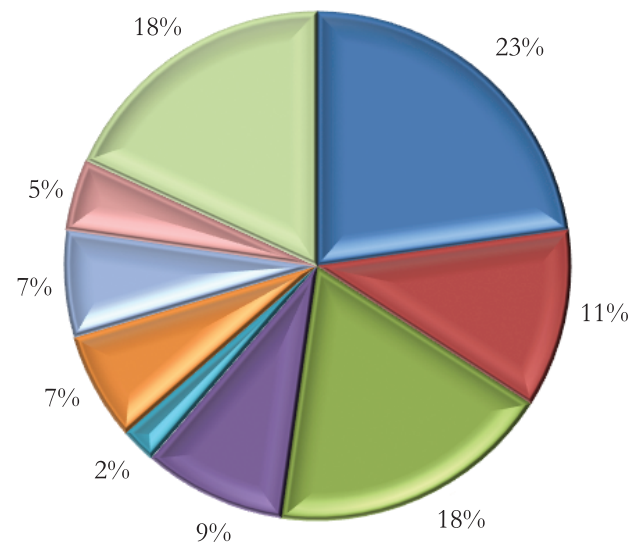

Figura 4. População-alvo nos trabalhos do campo social.

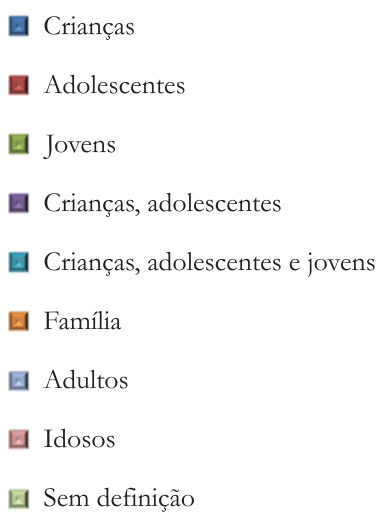

D Crianças

回 Jovens

口 Crianças, adolescentes

口 Crianças, adolescentes e jovens

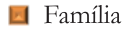

回 Adultos

Sem definição 
é histórica, fruto de processos de formação graduada que priorizaram, e muitos ainda priorizam, o enfoque sobre o desenvolvimento humano, notadamente o infantil. Esse fato se repete também no campo social, no qual se constatou uma grande proporção de pessoas debruçadas sobre as questóes da infância, vinculadas às situaçôes de vulnerabilidade social. Os trabalhos que tinham como foco crianças, adolescentes e jovens representavam $64 \%$ do total, ou seja, a grande maioria dos trabalhos reflete as intervençôes com essas populaçôes. É importante salientar que a "juventude" aparece fortemente vinculada aos trabalhos submetidos por um único grupo, o Núcleo UFSCar do METUIA, que tem se dedicado a esta temática em suas açóes de ensino, pesquisa e extensão (LOPES, 2006; LOPES et al., 2008, 2010).

Outro destaque se faz com relação à recente ampliação do debate sobre a atuação dos terapeutas ocupacionais junto à Política Nacional da Assistência Social e seu desdobramento no Sistema Único de Assistência Social - SUAS (BRASIL, 2005). Como decorrência desse processo, aparece nos trabalhos o termo "famílias", como um grupo com uma concepção definida, conforme especificado pelo Serviço de Proteçáo e Atendimento Integral à Família (PAIF), previsto pelo SUAS (BRASIL, 2005).

Por fim, assinalamos a escassez de trabalhos em relaçáo à populaçáo adulta e aos idosos. Os trabalhos referentes aos adultos eram três, sendo que abordavam os moradores adultos em situação de rua e os portadores de HIV/AIDS. Com relação à população idosa, apenas dois resumos se detiveram nessa temática. Esta evidência nos faz refletir sobre como os terapeutas ocupacionais, para além de uma perspectiva clínica, têm lidado com esses grupos populacionais, que são numericamente importantes e crescentes na constituição demográfica brasileira, especialmente os idosos, com relação aos quais são crescentes as demandas sociais nas camadas populares. Parece-nos que a terapia ocupacional na área de gerontologia vem se configurando de maneira importante, assim nomeando suas práticas, o que implicou, dados os procedimentos adotados por nós, a sua não seleçáo como questão do campo social. Essa é, pelo menos, a nossa esperança com relação a tão importante demanda.

Acerca dos Setores de Vinculação, temos que $39 \%$ dos trabalhos estiveram envolvidos como setor da assistência social (Figura 5). Podemos supor que se trata de intervenções em serviços e equipamentos sociais desse setor ou, ainda, de organizaçôes não governamentais que realizam serviços públicos indiretos mediante convênios e

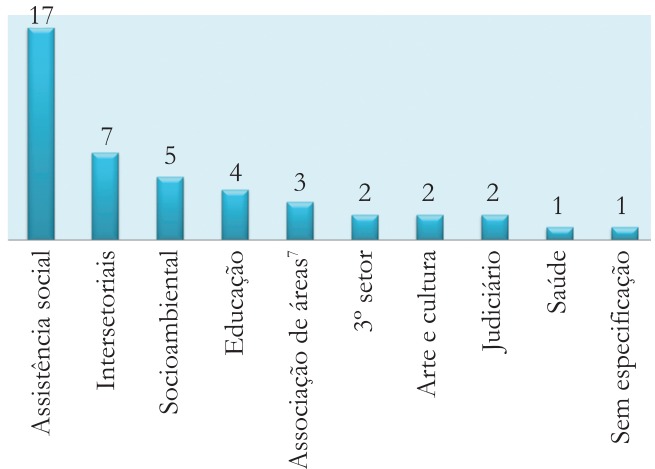

Figura 5. Setores presentes nos trabalhos do campo social ( $\mathrm{N}^{\mathrm{o}}$ de trabalhos).

financiamentos da assistência pública social. Nessa subárea, evidenciam-se sete trabalhos desenvolvidos em abrigos ou albergues para crianças e adolescentes, correspondendo a $41 \%$ do total de trabalhos na assistência social e a $16 \%$ do total de trabalhos do campo social.

Quando definimos essa categoria, partimos do pressuposto de que o setor que provê os recursos e/ou que realiza a intervençấo influencia no desenvolvimento da ação técnica, em seus limites e suas potencialidades. Esta classificação foi de difícil alcance, uma vez que nem todos os trabalhos explicitavam o setor a que se vinculava a experiência. O exemplo mais claro foi a inferência que fizemos ao inserir os "abrigos" e "albergues" como parte da assistência social, pois nem todos os trabalhos que trouxeram esta temática declararam a vinculação do equipamento social. Isso é diferente quando se explicitam, por exemplo, os trabalhos realizados nos equipamentos como o Centro de Referência da Assistência Social (CRAS) e o Centro de Referência Especializado de Assistência Social (CREAS), que são instituiçóes implementadas para dar consecução e efetividade à Política Nacional da Assistência Social e, portanto, claramente colocadas nesse âmbito (BRASIL, 2005).

Além da dificuldade de categorização, é relevante destacar os trabalhos que declaravam envolvimento em diferentes áreas de intervenção, por nós denominados de intersetoriais, correspondendo a $16 \%$ do total. O campo social é um espaço de interface e de diferentes domínios de conhecimento que se constitui por meio de abordagens intersetoriais e interprofissionais, na medida em que se direciona pela busca do acesso a bens sociais de diversas ordens, de acordo com as necessidades dos sujeitos, individuais e coletivos. Assim, a presença dessa natureza de práticas demonstra a difícil e indissociável tarefa do campo de se constituir por meio da intersetorialidade. 


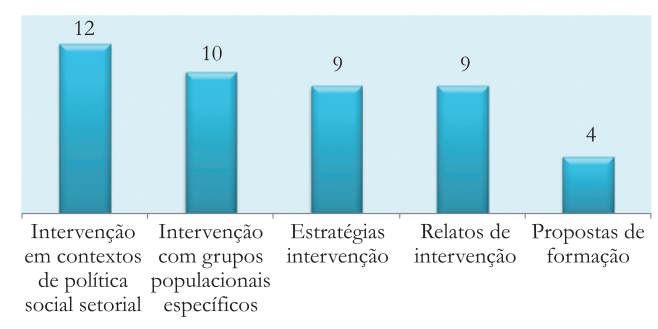

Figura 6. Temáticas centrais dos trabalhos do campo social ( $\mathrm{N}^{\circ}$ de trabalhos).

Ressaltam-se, ainda, os trabalhos socioambientais desenvolvidos, sendo que a questão das catástrofes ambientais foi prioritária nesse âmbito e, essencialmente, tem sido estudada e discutida por colegas latino-americanos, não se constituindo, até aqui, como uma problemática para os terapeutas ocupacionais brasileiros.

Outra análise realizada foi o levantamento das Temáticas centrais dos trabalhos, ou seja, o cerne do trabalho divulgado no evento. Para tanto, foram criadas categorias que pudessem refletir o debate trazido em cada resumo pelos autores, conforme a Figura 6.

Cada um dos itens compilados na Figura 6 foi detalhado no Quadro 1, com o intuito de se apresentar as categorias adotadas para delinear os trabalhos em cada subitem.

Esse panorama demonstra que o setor no qual o terapeuta ocupacional divulgou mais fortemente suas experiências foi o da assistência social, refletindo a recente expansão do Sistema Único de Assistência Social.

Já o item "Intervenção com Grupos Populacionais Específicos" destaca que 12 trabalhos, ou seja, $28 \%$ daqueles abordados no campo social, trazem a população-alvo a que se referem como centro da discussão. Essa informação reafirma o Figura 4, na medida em que, novamente, são as crianças que têm destaque.

Quando se fala do debate acerca das estratégias de intervenção em terapia ocupacional, encontra-se esse objeto em $21 \%$ (9) dos trabalhos do campo social. Há uma multiplicidade de açôes que podem ser compreendidas em diversas abordagens, trazendo propostas e recursos de intervenção na área. Observa-se uma predominância da questão do uso de atividades.

Por fim, tem-se outros $21 \%$ dos trabalhos dedicados à descrição de experiências e $9 \%$ com o foco na formação de profissionais.

\section{Voos sobre o campo: discutindo os dados encontrados}

Detemos-nos aqui em alguns apontamentos a partir da análise dos dados sobre os trabalhos apresentados e classificados como pertencentes à área social.

Inicialmente, destaca-se o fato de grande parte dos trabalhos se referir à temática da infância e adolescência, caracterizando-se como uma "porta de entrada" para as intervençóes no campo social. Como colocado anteriormente, há uma predominância de abordagens desenvolvimentistas na formação graduada, criando marcas importantes para o campo profissional, como a predominância de trabalho nesse âmbito. Outra questão a se acrescentar refere-se ao grande número de projetos sociais voltados ao público infantil, desde proposiçôes inseridas na atenção básica em assistência social, como os projetos realizados no contraturno escolar, que priorizam crianças, até açóes da atenção especializada em assistência social, como os abrigos. Assim, se lida com atividades desenvolvidas no contexto das IES e da formação graduada, com priorização do público infantil, bem como com um número expressivo de postos de trabalho com esse segmento.

Esse fato se repete quando consideramos o recurso terapêutico-ocupacional predominante, uma vez que observamos que muitos terapeutas ocupacionais vão para a área social, mobilizados pelo recurso do "brincar", novamente direcionados ao público infantil.

Vale também destacar uma recente discussão que se interpôs na área: a Política Nacional da Assistência Social. Nos anos de 2010 e 2011, terapeutas ocupacionais participaram das Conferências Regionais e da Conferência Nacional de Assistência Social, as quais tiveram como temática central os trabalhadores do Sistema Único de Assistência Social. A categoria esteve presente, defendendo a possibilidade de compor formalmente esse sistema, tomando como referência experiências acumuladas por alguns profissionais em diferentes locais do País. Como resultado desse processo, a terapia ocupacional, dentre outras categorias profissionais, foi reconhecida como uma profissão que pode atender às demandas socioassistenciais e de gestão do SUAS (BRASIL, 2011).

Ainda em torno dos setores, apontamos a Educação como destaque. Trata-se de um espaço em que terapeutas ocupacionais já desenvolvem práticas no interior da esfera social, avançando dos 
Quadro 1. Detalhamento das temáticas centrais dos trabalhos do campo social.

Intervenção em contextos de política social setorial: Política Nacional de Assistência Social (PNAS), Sistema Único de Assistência Social (SUAS), Centro de Referência em Assistência Social (CRAS*), Práticas comunitárias, Escola secundária, Penitenciária, Políticas para enfrentamento de catástrofes, Escola de bairro periférico, Distinção entre campo social e atenção básica em saúde.

Intervenção com grupos populacionais específicos: Adolescente abrigado, Adolescente em risco social, Niños trangresores, Crianças abrigadas, Adultos portadores de HIV/AIDS, Criança vitimizada e abrigada, Jovens Guarani.

Estratégias de intervenção: Atividades artísticas e culturais, Tecnologias sociais, Gestão social integral, Rodas de conversa, Linha do tempo, Atividades como recurso, Articulação e gestão em rede, Sustentabilidade socioambiental, Juventude pobre*, Adolescentes vítimas de abuso sexual.

Relatos de intervenção: Brincar para exploração territorial e cultural, Brincar para minimizar efeitos do abrigamento, Enfrentamento da violência, Brincar como prevenção do uso de drogas, Grupo terapêutico na escola, Sexualidade na escola, Catástrofes, Brincar em albergue, Percepção da violência da criança em situação de vulnerabilidade.

Propostas de formação: Curso preparatório para adoção, Catástrofes*, Estágio de terapia ocupacional no campo social.

*Com 2 trabalhos distintos.

discursos e intervençóes que se centram "unicamente" na inclusão da criança com necessidades especiais, sem desvalorizar a relevância dessas açóes, e partem para a colaboração na construção da "escola pública" como espaço privilegiado para a realização do acesso a bens sociais fundamentais, na perspectiva de uma escola democrática, universal e de qualidade, criadora de sentidos e projetos para a infância e para a juventude, sem restringir-se à questão da deficiência.

Além desses campos, é preciso assinalar a temática das ações de combate às catástrofes naturais trazidas por trabalhos de colegas latino-americanos. Percebemos que tal tema não tem ressonância na terapia ocupacional brasileira, sendo que duras realidades vivenciadas, como o terremoto de 2010 no Chile, produziram práticas nessa direção. Pode-se, também, vislumbrar essa área como um novo espaço de atuação social do terapeuta ocupacional.

Outro destaque relaciona-se à evidência de não haver uma base conceitual sólida nas referências apresentadas pelos trabalhos, sendo que os resumos demonstravam um uso simultâneo de abordagens diferentes, numa espécie de bricolagem de referências conceituais. Um exemplo de tal situação diz respeito aos relatos de intervençóes em abrigos, que apresentaram um número expressivo de trabalhos. Nestes, predominou uma abordagem do desenvolvimento infantil e da utilização do brincar como recurso benéfico para a criança, elementos certamente concernentes à infância; careciam, porém, daquilo que atropela efetivamente o desenvolvimento e o brincar de nossas crianças: a pobreza, o abandono familiar e/ou social, a vulnerabilidade e as violências a que estão submetidas, ou seja, a imensa desigualdade com que temos que lidar no Brasil e na América
Latina como um todo. Dessa maneira, não se trazem à cena as questóes institucionais, em especial as relaçóes entre os cuidadores e as crianças, podendo acarretar uma perspectiva de "harmonização" das relaçóes intrainstitucionais por intermédio de açóes do terapeuta ocupacional, fato já debatido e criticado por uma geração de profissionais em discussão com os processos de desinstitucionalização, amparados nos estudos de Erving Goffman e Franco Basaglia (BARROS; GHIRARDI; LOPES, 1999, 2002; BARROS; LOPES; GALHEIGO, 2007b).

Evidentemente que o abrigo, o desenvolvimento das crianças institucionalizadas e o brincar são elementos de extrema relevância para integrarem as intervençôes no campo social. Contudo, as bases atuais desse campo preveem, necessariamente, a discussão/composição com o SUAS, com a Política Nacional de Convivência Familiar e Comunitária (BRASIL, 2006) e com o próprio Estatuto da Criança e do Adolescente (BRASIL, 1990), que vêm criando outros mecanismos de ação com essa população, como, por exemplo, projetos de colocaçáo de crianças e adolescentes em famílias substitutas. Preocupa-nos a possibilidade de não estarmos integrados às discussões do campo, tampouco criando estratégias que se deem na perspectiva legislativa atual, em uma direção mais humanizada e para a promoção da convivência familiar e comunitária, ao invés da institucional, reproduzindo formas e concepçóes ultrapassadas para o necessário atendimento da criança em situação de abandono e/ou de negligência.

Essa análise nos faz supor que os terapeutas ocupacionais têm construído suas bases teóricometodológicas após serem convocados a exercer seu 
trabalho profissional na área, dificilmente trazendo estudos prévios de seu período de formação graduada. Tal suposição apoia-se no fato de o campo social ser, ainda, uma área com poucos docentes trabalhando as competências, habilidades e conteúdos específicos necessários nos cursos de graduação. São poucas as disciplinas obrigatórias que contemplem a área entre os diferentes projetos político-pedagógicos, resultando num processo de formaçáo pelo qual os estudantes não necessariamente têm contato com o campo em seu período de graduaçáo (LOPES; PAN, 2012). O início de atuação e reflexão nesse âmbito ocorre, muitas vezes, num segundo momento, quando se precisa lidar com uma oportunidade de trabalho, seja por um concurso público, seja em projetos sociais executados pelas organizaçôes não governamentais, ambas, situaçóes ascendentes em termos de espaços de trabalho para os terapeutas ocupacionais.

Entretanto, é preciso se questionar quais referenciais são cabíveis ao campo e como os profissionais têm criado os diálogos entre as diferentes áreas, na perspectiva de se indagar como o uso de diversos pressupostos - como clínico, desempenho ocupacional, reabilitação psicossocial, terapia ocupacional social etc. - é prejudicial ou salutar no que tange ao desenvolvimento da área social. Sáo perguntas sem respostas fechadas ou prontas, pois requerem tempo, longo prazo, e dependem das reflexôes teóricas e metodológicas em torno de como vão se desenhando as práticas terapêuticoocupacionais no campo social.

No diálogo com as políticas sociais, temos vivenciado um debate em torno das delimitaçóes das áreas e das suas contribuiçôes concernentes ao campo. Mencionamos a discussão das categorias profissionais para a composição oficial da Política Nacional de Assistência Social, quando foi formalmente questionado a todos, incluindo os terapeutas ocupacionais, suas contribuiçóes referentes à dimensão social de sua intervenção. Como resposta, não se aceitavam justificativas atreladas ao setor Saúde, não cabendo, por exemplo, a colocação de proposiçóes clínicas de intervenção, na medida em que elas são compreendidas no interior daquele setor e não na Assistência Social. A não aceitação de tais argumentos foi extremada no interior dos debates nas conferências públicas de assistência social, quando se cortava a palavra do profissional que não soubesse defender sua pertinência sem lançar mão do apoio referenciado em outros setores. Naquela ocasião, conseguimos fazer o debate e fomos incluídos formalmente como profissionais da Assistência Social.

Ocorre que se quisermos ocupar outros espaços de intervenção, avançando para o campo social e lidando com suas questóes teóricas e metodológicas para a açáo com sujeitos, individuais e coletivos, com demandas próprias, não relacionadas à saúde stricto sensu, precisaremos aprofundar os pressupostos em voga, inquirir sua pertinência a uma prática coerente, compromissada e competente técnica, ética e politicamente.

\section{Considerações finais}

Em um contexto mundial de crescentes desigualdades socioeconômicas, debruçar-se sobre as questôes sociais e desenvolver reflexóes para sua compreensão, assim como para o fomento de metodologias de intervenção, tem uma função social técnica de relevância. Nessa perspectiva, as práticas em terapia ocupacional social têm ganhado visibilidade e destaque no cenário profissional, demonstrando uma ascendência da área e um número maior de possibilidades de intervençóes nessa direção.

A mudança contemporânea do mundo do trabalho, a consequente emergência de situações sociais decorrentes dos processos de empobrecimento/ desigualdade social atingindo também países desenvolvidos, assim como os problemas socioambientais e a necessidade da concepção de estratégias de enfrentamento a catástrofes, têm se interposto como temáticas que trazem o terapeuta ocupacional para a discussão de formas de implementação de sua preocupação central: a inserção social, a autonomia e a liberdade de determinados grupos populacionais.

Estáo postos os desafios para os terapeutas ocupacionais com relação aos processos socioeconômicos e culturais, na direção do questionamento de suas bases conceituais para o enfrentamento de novas demandas, dos recursos necessários para a intervençáo, de maneira a se continuar respeitando, todavia, a rica diversidade sempre presente nas práticas da área.

\section{Referências}

BARROS, D. D.; GHIRARDI, M. I. G.; LOPES, R. E. Terapia ocupacional e sociedade. Revista de Terapia Ocupacional da Universidade de Sáo Paulo, v. 10, n. 2-3, p. 69-74, 1999. 
BARROS, D. D.; GHIRARDI, M. I. G.; LOPES, R. E. Terapia Ocupacional Social. Revista de Terapia Ocupacional da Universidade de São Paulo, v. 13, n. 2, p. 95-103, 2002.

BARROS, D. D.; LOPES, R. E.; GALHEIGO, S. M. Projeto Metuia: apresentação. In: SIMPÓSIO DE TERAPIA OCUPACIONAL SOCIAL, 1., 2007, Goiânia. Anais... Goiânia: Associação dos Terapeutas Ocupacionais de Goiás, 2007a.

BARROS, D. D.; LOPES, R. E. ; GALHEIGO, S. M. Terapia ocupacional social: concepçôes e perspectivas. In: CAVALCANTI, A.; GALVÂO, C. (Orgs.). Terapia ocupacional - fundamentação e prática. Rio de Janeiro: Guanabara Koogan, 2007b. p. 347-353.

BRASIL. Estatuto da criança e do adolescente. São Paulo: Cortez, 1990.

BRASIL. Ministério do Desenvolvimento Social e Combate à Fome. Secretaria Nacional de Assistência Social. Sistema Único de Assistência Social - SUAS. Norma Operacional Básica NOB/SUAS: Construindo as Bases para a Implantaçáo do Sistema Único de Assistência Social. Brasília: Ministério do Desenvolvimento Social e Combate à Fome, 2005.

BRASIL. Ministério do Desenvolvimento Social e Combate à Fome. Secretaria Especial dos Direitos Humanos. Plano Nacional de Promoção, Proteção e Defesa do Direito de Crianças e Adolescentes à Convivência Familiar e Comunitária. Brasília: Ministério do Desenvolvimento Social e Combate à Fome, 2006.

BRASIL. Conselho Nacional de Assistência Social - CNAS. Resolução no 17/2011, de 20 de junho de 2011. Ratificar a equipe de referência definida pela norma operacional básica de recursos humanos do Sistema Único de Assistência Social - NOB-RH/SUAS e Reconhecer as categorias profissionais de nível superior para atender as especificidades dos serviços socioassistenciais e das funções essenciais de gestão do Sistema Único de Assistência Social - SUAS. Diário Oficial da República Federativa do Brasil, Brasília, DF, 21 jun. 2011. Seção 1.

CONGRESSO BRASILEIRO DE TERAPIA OCUPACIONAL, 12.; CONGRESSO
LATINO-AMERICANO DE TERAPIA OCUPACIONAL, 9., 2011, São Paulo. Cadernos de Terapia Ocupacional da UFSCar, v. 19, 2011. Suplemento Especial.

CONSELHO FEDERAL DE FISIOTERAPIA E TERAPIA OCUPACIONAL - COFFITO. Resolução no 371/2009, de 6 de novembro de 2009. Dispóe sobre a alteração do artigo $1^{\circ}$ da Resolução COFFITO nº 366. Diário Oficial da República Federativa do Brasil, Brasília, DF, 30 nov. 2009. Seção 1.

CONSELHO FEDERAL DE FISIOTERAPIA E TERAPIA OCUPACIONAL - COFFITO. Perguntas mais frequentes. Quantitativo de profissionais. Disponível em: <http://www.coffito.org.br/faqs/faq.asp >. Acesso em: 25 fev. 2012.

CONSELHO REGIONAL DE FISIOTERAPIA E TERAPIA OCUPACIONAL DA TERCEIRA REGIÁO - CREFITO-3. Pesquisa de inscritos. Estatística de profissionais. Disponível em: <http://www.crefito. com.br/app_site/est_prof.asp >. Acesso em: 25 fev. 2012. FREIRE, P. Educação como prática da liberdade. 8. ed. Rio de Janeiro: Paz e Terra, 1978.

LOPES, R. E.; PAN, L. C. O Ensino de Terapia Ocupacional Social nas Universidades Públicas no Estado de São Paulo. São Carlos: FAPESP/UFSCar, 2012. 103 p. Relatório Final.

LOPES, R. E. et al. Educação profissional, pesquisa e aprendizagem no território: notas sobre a experiência de formaçáo de terapeutas ocupacionais. O Mundo da Saúde, v. 34, n. 2, p. $140-147,2010$

LOPES, R. E. et al. Juventude pobre, violência e cidadania. Saúde e Sociedade, v. 17, n. 3, p. 63-76, 2008.

LOPES, R. E. Terapia ocupacional social e a infância e a juventude pobres: experiências do Núcleo UFSCar do Projeto METUIA. Cadernos de Terapia Ocupacional da UFSCar, v. 14, n. 1, p. 5-14, 2006.

REIS, T. A. M.; BARROS, D. D.; UCHIDOMARI, I. Y. A terapia ocupacional social nos congressos brasileiros (1997-2007): desafios e debates de um campo emergente. Revista de Terapia Ocupacional da Universidade de São Paulo, v. 21, n. 2, p. 111-120, 2010.

\section{Contribuição dos Autores}

Roseli Esquerdo Lopes: Concepção inicial do trabalho. Patrícia Leme de Oliveira Borba e Carla Regina Silva: Coleta e organização dos dados. Todas as autoras participaram das análises, da elaboração e redaçáo do texto.

\section{Notas}

${ }^{1}$ Parte da discussão deste trabalho foi apresentada no II Simpósio Internacional de Terapia Ocupacional Social, realizado no dia 12 de outubro de 2011, compondo a programaçáo do XII Congresso Brasileiro de Terapia Ocupacional e IX Congresso Latino-americano de Terapia Ocupacional.

${ }^{2}$ METUIA, palavra da língua nativa indígena brasileira, da comunidade bororo, que significa amigo, companheiro e que nomeia o grupo interinstitucional de estudos, formação e açôes pela cidadania de crianças, adolescentes e adultos em processos de ruptura das redes sociais de suporte, formado, atualmente, por docentes, profissionais e estudantes, de graduação e de pós-graduação, da Universidade Federal de São Carlos, da Universidade de São Paulo e da Universidade 
Federal de São Paulo. Sua proposta tem sido desenvolver projetos no âmbito do ensino, da pesquisa e da extensão em terapia ocupacional social. Dentre suas atividades mais importantes, temos os programas de intervençáo de terapia ocupacional em suas interconexóes com os setores da assistência social, da cultura, da educação e da saúde. A intervenção efetivada decorre de projetos de extensão universitária e das parcerias estabelecidas em cada um deles, vindo a acontecer em espaços públicos, espaços comunitários e instituições sociais, como escolas, abrigos, centros comunitários e outras organizaçóes sociais que atendem a populaçóes em processo de ruptura de redes sociais de suporte (BARROS; LOPES; GALHEIGO; 2007a).

${ }^{3} \mathrm{O}$ evento recebeu financiamento da FAPESP (Fundação de Amparo à Pesquisa do Estado de São Paulo) e da Universidade de Sáo Paulo, teve o apoio da Associação dos Terapeutas Ocupacionais do Estado de São Paulo (ATOESP), e foi realizado pela seguinte Comissão Organizadora: Patrícia Leme de Oliveira Borba, Denise Dias Barros, Roseli Esquerdo Lopes, Ana Paula Serrata Malfitano, Carla Regina Silva, Debora Galvani, Marta Carvalho de Almeida, Waldir Pierote, Sandra Maria Galheigo e Samira Lima Costa.

${ }^{4}$ Compunham os demais eixos do XII CBTO e IX CLATO os temas: "Políticas Públicas e Gestão", "Formação em Terapia Ocupacional", "Pesquisa em Terapia Ocupacional", "Identidade(s), Ocupação e Episteme da Terapia Ocupacional", "Ocupação, Cultura e Direitos Humanos".

${ }^{5}$ Integrou a sessão do II SITOS “Em Debate: Experiências de Terapia Ocupacional no Campo Social”, apresentada por Patrícia Leme de Oliveira Borba e Carla Regina Silva.

${ }^{6} 8 \%$ eram de dois autores, $23 \%$ eram de três autores, $30 \%$ de quatro e $25 \%$ tinham cinco autores, lembrando que, pelas normas de submissão definidas pela organização do evento, havia o limite máximo de cinco autores por trabalho.

${ }^{7}$ Associação de áreas refere-se à: assistência social e saúde, assistência social e educação, saúde e educação. 